Mr. Middlemore was an exceedingly modest man, and of very tolerant judgment. He was free from any self-assertive manner, and in consequence often gave others the impression of a diffidence which was really due to his habit of carefully weighing matters before decision. When once he had made up his mind he was firm. He had a quiet, rich humour, which those who knew him well appreciated, but he was very reticent, and did not readily admit persons to his confidence. $\mathrm{He}$ was scrupulously conscientious in his dealings with his brethren; simple, kind, generous, and always maintained a high standard of professional life.

As one who knew him intimately in his late years, and one greatly indebted to him for assistance and guidance in early life, I am happy in having this opportunity of making permanent this memoir of Mr. Richard Middlemore.

\title{
COMMUNICATIONS
}

\section{ON THE CHARACTER AND THE TREATMENT OF SCROFULOUS INFLAMMATIONS OF THE EYE ${ }^{1}$}

BY

\author{
L. K. WOLFF,
}

OCULIST-BACTERIOLOGIST; FIRST ASSISTANT IN THE LABORATORY FOR HYGIENE OF THE AMSTERDAM UNIVERSITY.

Notwithstanding a great many experimental and clinical observations, and notwithstanding ingenious reasonings during the past 80 years, we have not advanced very much in our study of the phenomena of scrofulous inflammation of the eye, nor have the methods of treatment undergone any important change. About 1850, Mackenzie, the famous English oculist, wrote ${ }^{2}$ : "We must confess that in many cases this inflammation of the eye, i.e., the scrofulous one, is very obstinate. When we are asked why it does not yield to the best treatment, we, in turn, ask why is it that in a scrofulous individual the inflammation of the glands of the neck is so obstinate, continues to discharge pus, notwithstanding all remedies. . . It is the scrofulous constitution which causes the extremely long duration of this inflammation of the eye, just as it is responsible for the long duration of the other scrofulous inflammations, and as long as we have not found a radical remedy . for scrofula, this inflammation will mock at the best combined and most accurately applied method of treatment."

Not much has changed since that time. The local treatment may have improved to some extent, but it cannot prevent relapses, 
and the general treatment of scrofula has certainly not improved markedly since then. We do know that a stay in fresh-air colonies, especially at the seaside, can, together with good nourishment, do our scrofulous children much good. But for a great many this is unattainable; for others, four or six weeks in the summer are far too little, so that very soon after their return to their families they lose their colour and their healthy looks, and again show all the signs that characterize scrofula.

In this essay I hope to show that we are now in possession of a really efficacious and harmless remedy with which to combat scrofula.

In this report I shall, for the time being, confine myself to scrofulous inflammation of the eye, although I wish to say that this method can also be applied to other scrofulous conditions.

It would lead me too far to enter upon̈ a discussion of all theories concerning scrofula here. I understand scrofula to be a particular form of tuberculosis, viz., of the system of the lymphatic glands. This tuberculosis is generally caused by the human tubercle bacillus, sometimes, however, also by the bovine bacillus, especially in England, as opposed e.g., to Paris, where the bovine bácillus has seldom been found. We have not yet any data at our disposal concerning the nature of the tubercle bacilli in Holland.

In tuberculosis of the lymphatic glands, the glands of the neck and head are the ones most frequently affected, sometimes also the axillary and the supra- and infraclavicular glands, very seldom the inguinal ones. I have no data about the thoracic glands, but from the success of my therapy it would seem that these are not markedly affected in most cases.

An extensive examination of more than one hundred cases has taught me that pulmonary affections are very rare, as far as they can be detected by percussion and auscultation (as far as I am concerned, I have never found them).

With adults symptoms of scrofula are not so very rare, although this fact is hardly mentioned in the literature. ${ }^{3}$

We often find in scrofulous patients scrofulous inflammations of the eye. Von Pirquet's reaction has taught us that where we find this inflammation of the eye, even without any other evident symptoms of scrofula, tuberculosis is present. According to the observations of others and of myself this reaction is positive in 90 to 100 per cent. of all cases. Very early in the bacteriological era staphylococci were nearly always found in the conjunctival sac of phlyctenular patients. The non-ulcerating phlyctenule, however, contains neither staphylococci nor tubercle bacilli. Its histological construction does not resemble tuberculosis very much, but is more like an ordinary inflammation. ${ }^{4}$

Experiments on animals to produce phlyctenules either with 
tubercle bacilli or with staphylococci or with the poisons of both, have only had unsatisfactory results. The experiments have now and then succeeded in producing a small nodule, the size of a pin's head, which histologically resembled the human phlyctenule, but the great difficulty of producing them and the slight inflammation which results, scarcely justify us in classifying these formations with human phlyctenules. And yet some theories have been based on these experiments, accounting for all the phlyctenular inflammations of the eye.

Whereas Axenfeld in his "Bacteriologie des Auges," does not pronounce a definite opinion, Rosenhauch ${ }^{5}$, after a series of experiments, has expressed a theory which has also been defended by Straub in earlier years on clinical grounds, that the phlyctenules are formed by the co-operation of internal (tubercle toxins) and external causes (poisons of other bacteria, especially of the staphylococcus aureus). The success of his experiments, consisting in bringing staphylococci into the eyes of tuberculous guinea pigs after scarification of the conjunctiva could not be obtained by later experimenters. I have had no success either.

Straub $^{6}$ has given us his opinion that in persons with latent tuberculous foci, débris of tubercle bacilli or of the diseased tissues enter the circulation, and can produce metastatic tuberculosis. This metastatic tuberculosis is generally an attenuated tuberculosis. In principle there is not a great difference between scrofulous inflammation of the eye, and a mild form of tuberculosis (keratitis diffusa tuberculosa, cyclitis, choroiditis, iritis serosa, scleritis).

Rubert $^{7}$ is of about the same opinion as Rosenhauch. He thinks that a tuberculous infection of the organism is necessary for the production of phlyctenules. But besides some external irritant is necessary, e.g., toxins of staphylococci, chemical substances, diseases of the nose, irritation by light. Rubert does not believe in a so-called hypersensitive reaction.

Stargardt ${ }^{8}$ thinks that phlyctenular inflammation of the eye is real tuberculosis, which is caused by bacilli in conjunctiva and cornea, but that a very particular degree of immunity must be present for its production, as is also recognized in the milder forms of internal tuberculosis.

Finally, Weekers ${ }^{9}$ believes that the phlyctenules are caused by tuberculous toxins. He compares the phlyctenules with the tuberculides of the skin and anatomically he also finds a great similarity in their construction. All these theories agree in so far that the phlyctenule is a manifestation of tuberculosis. But they leave a number of clinical facts unexplained, which I shall now mention.

(1) We know that scrofula is a localization of the tuberculous process in the lymph glands. Why is it then that we do not meet with phlyctenules when tuberculosis is confined to some other 
localization, viz., pulmonary tuberculosis (phthisis), abdominal tuberculosis, tuberculosis of the kidneys ? These processes can also be mild and can be cured.

(2) Straub ${ }^{10}$ has indicated that in children having a so-called mild tuberculosis of the eye, we see the same concomitant symptoms as in children having scrofula. I have extended this investigation to adults with a mild form of tuberculosis of the eye, and I am in a position to state that almost without exception these patients have swollen lymph glands of the neck and head. This phenomenon is so constant that at the present time it is of aid to me in diagnosing the tuberculous from the other chronic diseases of the eye. I may thus maintain that benign tuberculous affections of the eye almost exclusively appear in scrofulous individuals, or in those who formerly were scrofulous.

(3) Scrofulous conditions of the eye very often only affect one .eye and recurring attacks only affect that eye. It is difficult to explain this by metastasis. In such a case the right and left eye will probably have equal chances of being affected.

(4) In scrofulous children phlyctenules sometimes appear after instilling tuberculin (test of Calmette).

Weekers obtains the same result in animals, but undiluted tuberculin must be repeatedly instilled, and success was obtained almost exclusively in tuberculous animals. Besides, the phlyctenules are very small. Phlyctenules also appeared after a subcutaneous injection of tuberculin (I once saw a phlyctenule after exposing the lymph glands of the neck to Röntgen rays: post or propter?).

(5) As far as I know, phlyctenules do not appear spontaneously in animals, even after the test of Calmette.

It will be evident that these well known facts cannot easily be accounted for by the above-mentioned theories. If we accept, together with Straub, Stargardt, and Weekers, that the phlyctenules are tuberculous metastases, either of living bacilli or of toxins, the often occurring unilaterality is hardly to be explained.

Besides, why do we not find these metastases in pulmonary tuberculosis, where toxins, and very often living bacilli, certainly enter the bloodstream. Stargardt said that for their production a very distinct immunity must be present. Do they occur in tuberculosis? Certainly we know since Koch and later Römer thoroughly investigated this matter, that an organism reacts in a different way from injected tubercle bacilli, according to whether it was formerly tuberculous or healthy. In the latter case the process lasts very long, in the former it has a stormy progress, but is cured much sooner. It is well known that tubercle bacilli injected subcutaneously into a healthy guinea pig, only produce an ulcer after some weeks, which generally remains till the end of its life. 
In a tuberculous guinea pig, however, this ulcer appears after a few days, and is cured again after some weeks.

We also know that tuberculous organs react in a very specific way to the injection of the tuberculous poison, tuberculin, in the body. We then get a violent, very often a haemorrhagic inflammation of the affected organ, whereas the organs which are not affected do not react at all.

We are familiar with a similar phenomenon in other bacterial inflammations, e.g., by staphylococci and trichophyton. Here we see sometimes the phenomenon that after an injection of the bacterial poison the healed spots become inflamed. As an example hereof I may mention a case under my own observation of a patient who had several times gone through a cycle of furuncles. When I injected the patient for the first time with staphylococcus vaccine, after the method of Wright, he not only had fever (a general reaction), but also a reddening of all the spots of the skin, 'where furuncles had been formerly, although before the injection nothing was to be seen of them.

So in chronic infectious diseases we see immunity and hypersensitiveness reactions appearing side by side. Besides, we have learned from the above that these reactions may affect certain organs or parts of organs locally, and that these reactions may occur more especially in those places which have been the seat of a former process whigh has been cured.

If we apply this knowledge to phlyctenular inflammations of the eye, we must, in my opinion, also accept here that the patient has had a tuberculous process in his eye before, which, however, was cured by the natural power of resistance of the organism. That eye has now become hypersensitive to the tuberculous poison.

Now we only have to accept that tuberculous poisons are now and then mobilized out of the tuberculously inflamed lymph glands. It is almost self-understood that this will especially be the case when the external surroundings of the patient are unfavourable. Hence the manifold appearance of phlyctenules in poor scrofulous children, and also after intercurrent diseases, e.g., measles. I cannot yet decide whether external influences affecting the eye can also co-operate (e.g., the very frequent appearance of phlyctenules in trachoma).

As a proof of the first part of this hypothesis I may add that Schreiber ${ }^{11}$ has told us that in 25 per cent. of his 200 cases of phlyctenular inflammation of the eye he found tuberculous foci, or the scars thereof in the chorio-retina.

That phlyctenules do not appear spontaneously in animals may be explained by the fact that the human being is the most sensitive organism for tuberculin.

But the localization of tuberculosis as is seen in scrofulous 
patients is only seldom met with and consequently this is also the case with the primary foci in the eye.

As far as I could conclude from the literature that was at my disposal, only pigs seemed to show symptoms of isolated tuberculosis of the glands of the neck and head now and then. It will be interesting to examine the eyes of these animals with such inflammations minutely when more pigs are being killed again. The pig, however, is much less sensitive to tuberculin than the human being. And therefore we can .understand why phlyctenules in these animals are not reported. But still some difficulties remain, such as the simultaneous appearance of eczema and phlyctenules which is so often seen in scrofulous children. It would lead me too far to discuss the entire eczema theory here, but in the light of what has been mentioned above, I may say that the staphylococci also play a secondary part in the eczema, that they generally appear in scrofulous persons in certain places, in the corners of the nostrils, near or behind the ears, etc., and that I do not think it improbable that primarily those spots have also been the seat of tuberculous foci which have not been detected. The rest can then be accounted for the same way as in the eyes.

The fact that scrofulous patients generally react more strongly to tuberculin than other tuberculous patients, as seen in the results of the skin reactions of von Pirquet, is another support of our opinion.

The experimental phlyctenules do not quite belong to the cadre of our theory. But first of all we should not forget that the results obtained are very small and insignificant, and almost exclusively appear in tuberculous animals. Now we know that in individuals with tuberculosis the non-affected organs are more sensitive to tuberculin than those in normal persons, e.g., reaction of von Pirquet, and consequently these, though very insufficient experiments with the animals, do not seem to be contradictory to my theory.

I think it is very difficult to ascertain whether phlyctenules are caused by living bacteria or by dead ones or by their poisons. As far as I am concerned, I am of the opinion that the phlyctenules are caused by dead bacilli or poisons, considering the transitory character of the process and the rapid recovery, as well as the phlyctenules after instilling tuberculin. So the mild tuberculosis of the eye would be caused by living bacilli. But this opinion of mine has not been founded on more definite experiments so far. The inoculation of animals with the material from benign tuberculosis of the eye has only met with success in the smallest number of cases.

My hypothesis is most closely related to that of Stargardt, which coincides with my own in other things too, especially in the facts and phenomena observed in tuberculosis of the skin. It is a new 
observation, however, that I make when saying that I think I may take for granted that a primary tuberculous focus has existed in the eye itself (which explains its hybersensitiveness) appearing at the same time as, or shortly after the invasion of the lymph glands by tubercle bacilli, but which is cured again without having shown many symptoms.

I must say a few more words about the staphylococci. I consider their rôle a secondary one, but notwithstanding that fact not without importance. In many diseases we now see certain bacteria appear regularly, although these bacteria are not the cause of the disease. I shall only mention the paratyphus bacilli with hog cholera, the streptococci with scarlet fever, the proteus bacilli with typhus, the strepto- and pneumococci with influenza. In the more advanced stages of pulmonary tuberculosis the streptococci probably also play an important part. In all these diseases the resisting power in the body against these secondary bacilli is probably weakened, so that they can exert their deleterious effect. I look upon the influence of the staphylococci in the inflammations of the eye which we are discussing in exactly the same way. They can intensify secondarily the ulcers of cornea and conjunctiva. In consequence therefore one must certainly take these bacteria into account where the therapy is concerned.

What, then, as a result of the above-mentioned view, are the consequences we must draw concerning the therapy of our scrofulous inflammations of the eye? We must be able to influence the process in two ways :

(1) By removing the tuberculous foci, which, in the broadest sense of the word, send out the tubercle poisons.

(2) By decreasing the eye's sensitiveness to tuberculin.

The second method has been tried repeatedly by injecting tuberculin, the tuberculin cure. With the exception of a single report of good results in the literature, it has not had much success. Perhaps one has not had enough patience or faith in the treatment. But this treatment is certainly a very long and difficult one. Personally, I have not had the slightest success with it. The first method promises more, for it is not impossible to remove the tuberculous foci in scrofula surgically in a great many cases, and this very often produces good results. The first case I remember concerned a girl who had been treated for more than half a year in Prof. Straub's clinic where I was then house-surgeon. Every time when she was at the point of leaving the clinic she had a recurrence. Although at that time we only had a vague idea of the aetiology, we decided to take away the lymph glands after prolonged discussion of the matter, and after the operation there were no more recurrences.

Since then a few other cases were operated upon; but the 
comparatively severe character of the operation was a great drawback; also the possibility of miliary tuberculosis after the operation. Besides renewed inflammation of the lymph glands occurred rather often, which had a disheartening effect upon the patient. Still, this first observation has deeply impressed me, and when in 1915 I received a patient with the worst scrofulous inflammations I had ever seen, who had not only facial lupus, but also many lymph glands that could easily be extirpated, I again proposed the operation, and I have had very good results. The girl, who for years and years had had relapse after relapse, and who had also been treated in a university clinic for a long time, had no more relapses during the half year she remained under observation. Very soon afterwards I saw the favourable results of the treatment with Röntgen rays on tuberculous lymph glands, and I immediately understood that this must be our treatment of scrofulous inflammations of the eye. I found my colleague, Dr. van Ree, willing to treat my patients with $\mathrm{X}$ rays, and $\mathrm{I}$ can show you the result by the following table:

\begin{tabular}{|c|c|c|c|c|c|c|c|c|c|}
\hline & 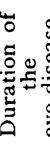 & & 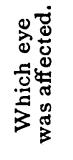 & & & 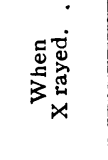 & 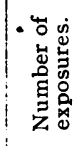 & 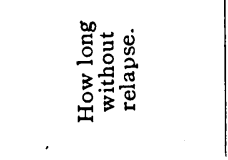 & 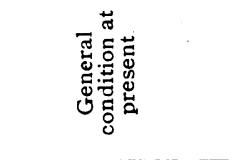 \\
\hline (1) & & years & R.L. & $24 y$ & ears & 1916 & 4 & 2 years & Good. \\
\hline (2) & 2 & , & L. & & .. & 1916 & 2 & $1 \frac{1}{2}$, & Good. \\
\hline (3) & 2 & , & L. & 9 & ", & 1917 & 4 & 1 year & $\begin{array}{l}\text { Relapse, glands } \\
\text { of the neck. }\end{array}$ \\
\hline$(4)$ & 17 & , , & R.L. & 21 & , & 1917 & 5 & 1 , & Very good. \\
\hline$(5)$ & & year & $\mathrm{R}$. & 29 & ", & 1917 & 10 & 1, & $\begin{array}{l}\text { Relapse, glands } \\
\text { of the neck. }\end{array}$ \\
\hline (6) & & years & R.L. & 27 & , & 1917 & 4 & 1, & Good. \\
\hline (7) & & year & R.L. & 26 & ", & 1917 & 5 & 1, & Very good. \\
\hline (8) & & years & L. & 9 & , & $1917-18$ & 5 & $\frac{3}{4} \quad$, & Good. \\
\hline (9) & $2 \frac{1}{2}$ & . & R.L: & 13 & , & $1917-18$ & 5 & $\frac{1}{2} \quad$, & Good. \\
\hline (10) & 2 & " & L. & 17 & ", & 1918 & 2 & 3 months & Good. \\
\hline (11) & 9 & , & L. & 37 & ,. & $1916-17$ & 4 & 1 year & Very good. \\
\hline (12) & 7 & , & $\mathrm{R}$. & 13 & , & 1917 & 6 & $\begin{array}{l}\text { Relapse : } \\
\text { remained away } \\
\text { during treatment }\end{array}$ & $\begin{array}{l}\text { Relapse, glands } \\
\text { of the neck. }\end{array}$ \\
\hline (13) & 3 & " & R.L. & 18 & ", & $1917-18$ & 4 & Relapse & Thoracic glands. \\
\hline (14) & & year & L. & 37 & , & 1916 & 4 & 1917 & \\
\hline
\end{tabular}


So on the whole the results are very good.

Of course, I only had those cases exposed which relapsed repeatedly. I must say a few more words about my bad cases, $11,12,13$. Case 11 had one very small phlyctenule in the course of the year, but has recurring attacks in the lymph glands. Case 12 has not come back to me after several X ray treatments, but was treated somewhere else. At a re-examination she had several recurring attacks in the lymph glands. Case 14 cannot be considered.

But about case 13 I must speak a little longer. Her lymphatic glands of the neck had been exposed to $\mathrm{X}$ rays, and at first with success. For half a year she did not complain, but now a phlyctenule period has come again, and yet there is little enlargement of the lymph glands of the neck. I have had the patient examined very carefully, and now it appears from the Röntgenphotograph that she has a distinct tuberculosis of the hilus glands. These we shall now have treated, and in this way we still hope to obtain a good result. She is now again three months without complaints. I must confess that I do not know anything definite about the hilus glands of the other patients. I examined their lungs as well as possible, and I never found any morbid symptom. I must admit, however, that a Röntgen examination of the hilus glands of the other patients belongs in the cadre of my work. Up to this time, however, I have never felt the need of it because the other cases progressed well without $\mathrm{X}$ raying the thorax, and from this good result I may conclude that the thoracic glands are probably not affected very seriously in most scrofulous patients.

The exposure took place every three weeks. In my patients no other surgical intervention has been necessary. When there is a marked softening of the glands the process of recovery can be hastened by aspiration of the pus. The $\mathrm{X}$ raying took place after filtration through an aluminium filter of $5 \mathrm{~mm}$. and after exclusion of the secondary rays by means of felt. Each time $4 \mathrm{H}$. were given at the utmost. When the lymph glands relapse it will be necessary to give another series of $\mathrm{X}$ ray exposures after a year, perhaps. No unfavourable symptoms were noticed after the exposures. Sometimes the patients complained of a dry mouth and a little pain in the throat, and sometimes the neck was somewhat red and swollen after the exposure. Only a very few times the patients got a general reaction, viz., fever, but it was never violent and soon passed away.

Besides, as already mentioned, once after an exposure phlyctenules appeared. When examining the patients again, it appeared to me that the exposures had not only kept away phlyctenules, but had also benefited them in other respects. Some told us spontaneously that they felt much better and stronger after the treatment. 
This was also to be seen by their external appearance. I think this of enough importance to be mentioned because the question arises whether other forms of scrofula, without the eye symptoms, should not also be treated with Röntgen rays. As far as I am concerned I should answer this question in the affirmative.

So I think I must conclude that patients with a recurring phlyctenular inflammation of the eye must be treated by exposing their tuberculous lymph glands to the $X$ ravs.

The phlyctenules themselves are not influenced by the exposures, nor are the ulcers of the corneae. Once in a while one remains powerless against these processes, and it seems hard to check the process notwithstanding the ordinary therapy, as washing of the eye, Pagenstecher's ointment, calomel, cauterization with the platinum wire, etc. I have, therefore, been trying to find a means of preventing the staphylococci from doing harm, as I consider them the most guilty elements in these serious cases. We have seen from Römer's investigation how ineffective our disinfectants are in the conjunctival sac, and how soon the chemicals are diluted and enter the nose with the lacrymal fluid. I have already pointed out that in my opinion much more is to be expected of disinfectants which do not easily dissolve, which, when introduced into the conjunctival sac in the form of powder or salve will, when dissolving, produce their effect in a concentrated form. The zinc fluorescein ${ }^{12}$ which I recommended in the diplobacillus conjunctivitis is of no use in the case of staphylococcus.

After that I considered the silver fluorescein recommended by Bruch for gonococci, which can only be dissolved in distilled water up to 2 per cent.; it is a red powder which dissolves very quickly, also in the lacrymal fluid. The saturated solution is not painful and is harmless to the eye. This solution in distilled water at once kills staphylococci (my own experiments). In a salt solution it works less strongly, being slowly changed to $\mathrm{AgC} 1$. As the lacrymal fluid also contains much $\mathrm{NaC} 1(+0.4$ per cent.) the effect in the conjunctival sac is not yet ideal, but, in my opinion, better than that of all the other familiar remedies. The main thing is that it penetrates into the conjunctival sac thoroughly. I generally used a 5 per cent. salve in white vaseline, and had some of it rubbed into the conjunctival sac every hour. This treatment is not painful and gave me very good results in some cases. An extremely obstinate case of ulcerated cornea in a little patient who was treated very thoroughly, but with whom cauterization did not help, was cured after two days. With obstinate blepharitis it often had a good effect too.

I wish finally to say a few words about the mild tuberculosis of the eye. As a matter of course, I also used the method of X raying the lymph glands of the neck here, and with this disease, too, I 
have seen its good results. Four cases have had no relapses up to the present time, only one had. The process itself, however, is not influenced by it, and this is of cardinal importance as opposed to the phlyctenular inflammation of the eye. Where, in other parts of the body we had seen such good results from the $\mathrm{X}$ rays on the tuberculous process of inflammation, it was evident that it would be wise to try also to expose the eye itself to $\mathrm{X}$ rays. $\left({ }^{13}\right)$ From Axenfeld's reports we know that this is really possible without injuring the retina, but his patients, who had tumours in the eye, were afflicted with cataract after some years. That is why I hesitated a long time before doing it. By chance $I$ am in a position to state that careful $\mathrm{X}$ raying with no more than $1 \frac{1}{2} \mathrm{H}$. every three weeks and filtration through $5 \mathrm{~mm}$. aluminium, does not injure the eye. In 1916, a patient with melanosarcoma conjunctivae was treated with $\mathrm{X}$ rays after the tumour had been extirpated. More than two years later, in 1918, this treatment had not injured the eye at all. The lens was still perfectly clear. A recurring attack of sarcoma obliged me to extirpate and then I could determine that there were no histological alterations. 'So I have finally applied this method to some cases which I had observed quite a long time, and which had become worse notwithstanding all kinds of other therapy. Some of them seem to have had much benefit from it. The time of observation is too short to form a fixed judgment about the method. So I shall not say more of it now, although I myself am firmly convinced of its future.

\section{Conclusions}

First, a somewhat modified theory has been given of the aetiology of phlyctenular eye inflammations.

Second, in connection with this theory a new method of treatment is given, viz., the exposure of the lymph glands of neck and head to $X$ rays.

\section{REFERENCES}

I. From a lecture delivered in the assembly of the Netherlands Ophthalmological Society, December I 5 , 1918 . - 2. 4th edition, translated into French by Warlomont and Testelin, Paris, I856,
Vol. I, p. 797 seq.

3. See, however, Brauer in "Br. Beiträge zur Klinik der Tuberculose."

4. Cp. Weekers' Dissertation.

5. Archivf. Ophthal., Vol. LXXVI, I910.

6. Ned. 7ijdschrift voor Geneeskunde, 1912, Vol. II, I877.

7. Klin. Monatsbl. f. Augenheilk., Vol. L, p. 273.

8. Rericht der Ophth. Gesellsch. in Heidelberg, I916, p. 462.

9. Inaugural Dissertation, Brussels, I9fI. 
10. Loc. cit.

II. Bericht der Ophth. Gesellsch. in Heidelberg, 1916, p. $47 \mathrm{I}$.

12. Münch. Med. Wochenschr., 1919.

13. Whether the radium exposure, according to P:of. Koster, with 5 mgr. radium not filtered, influences the tuberculous process according to the same mechanism, I am not in a position to decide. That the treatment with Röntgen rays can have another effect than that with radium, according to Prof. Koster, is apparent from a calculation of Dr. E. H. Büchner, which shows that, roughly calculated, in my manner 100 times more energy per time unit is absorbed by the eye than with the exposure with $5 \mathrm{mgr}$. radium.

\title{
REPORT OF THE OPHTHALMIC, WORK DONE IN THE MESOPOTAMIAN EXPEDITIONARY FORCE DURING I9I7 and I9I8
}

\author{
BY \\ G. McPherson, Lięut.-Col., I.M.S., \\ CONSULTING OPHTHALMIC SURGEON, M.E.F.
}

PRACTICALLY all the eye work of this force during the years 1917 and 1918 was done at the three ophthalmic centres of Busra, Amara, and Baghdad. It is found from experience that in a comparatively small branch of medicine such as ophthalmology it is much more satisfactory for cases in any given area to be examined and treated at a centre by an ophthalmic specialist than for each hospital to treat its own cases. The reasons for this are as follows :

(1) The average medical officer's knowledge of eye disease is very limited. Cases were constantly being sent in as cataract when the lenses were perfectly clear, the grayish colour of the lens of an elderly patient being mistaken for opacity. Most cases of inflammation were returned as conjunctivitis and had been treated with boric lotion.

(2) It obviates the same case being examined several times over. A man with an error of refraction might report sick at one hospital after another, but where there is a special centre this is impossible.

(3) It prevents unnecessary evacuation. When I was at Busra I was constantly having cases sent down which need not have been; for instance, a coolie with an old leucoma or a quiescent pterygium. In the earlier years of this campaign a large number of men suffering from artificially produced ophthalmia succeeded in this way in being invalided to India. This was before ophthalmic centres were established.

(4) It is more economical as regards the provision of drugs and equipment. 